\title{
Evaluation of Multimedia User Interface Design Method for M- learning (MobLearn): A Comparative Study
}

\author{
Shimaa Nagro \\ College of Computing and Informatics, Saudi Electronic University, Riyadh, Saudi Arabia \\ E-mail: s.nagro@seu.edu.sa \\ Maysoon Aldekhail \\ College of Computer and Information Sciences, Imam Mohammad Ibn Saud Islamic University, Riyadh, Saudi Arabia \\ E-mail: msdkhail@imamu.edu.sa
}

Keywords: M-learning, user interface, comparative study

Received: December 9, 2020

\begin{abstract}
The multimedia m-learning method (MobLearn method) is a holistic and functional method that includes the key steps, methods, and techniques for using multimedia to create m-learning interfaces. In this paper, the MobLearn process was evaluated by comparing it to one of the latest m-learning methods by Stanton and Ophoff (2013) which has the same function. A comparative case study was employed to examine the degree to which two m-learning approaches are similar in terms of interface architecture and their main characteristics, their differences and the primary function of features that occur in one of them but not in the other. Based on this comparative study, the final version of MobLearn method was introduced in two forms: high-level framework and method steps. In this version, the mapping strategies of m-learning were applied where the mapping techniques deal with a different set of information types and a large variety of media.
\end{abstract}

Povzetek: Primerjana je multimedijska metoda MobLearn z m-metodo Stantona in Ophoffa.

\section{Introduction}

We are currently undergoing a knowledge revolution in which computer-based communication and technology are increasingly evolving and affecting all aspects of our lives. One of the most important impacts of the technical revolution has been in the field of education and learning. E-learning can occur as synchronously or asynchronously either inside or outside a classroom. More recently, the introduction of M-learning as an extension of E-learning has led to great developments in mobile technologies. Mlearning is essentially the use of various mobile technologies to provide opportunities for learning anywhere and anytime using mobile phones, smart phones, PDAs, tablets and wireless networking technologies [1].

The recent emergence of technology such as mobile devices, multimedia interfaces, and m-learning has resulted in many mobile educational apps being developed. These kinds of programs have been developed to enable non-programmers to develop their own software for m-learning. Although these applications are effective in creating m-learning applications, they do not provide affordable, essential, design-based procedures to meet student requirements in design media selection.

The multimedia m-learning method (MobLearn method) presented in Nagro and Campion forms a complete and user-friendly method that encompasses the main steps, sub-steps, tools, and techniques required to produce m-learning interfaces using multimedia [2]. It includes all the stages required to build software applications that specialize in m-learning systems. The effectiveness of this method was evaluated using a case study on a historical topic, and the evaluation confirmed that the method's steps were not only effective for designers but also had a positive impact on multimedia user interface design for mobile learning. In addition, these authors published another research paper [3] explaining the steps of the proposed method, and evaluated the usability of the method using think-aloud protocol. The method encompasses the steps, tools, and techniques necessary to produce M-learning interface using multimedia.

In this particular research study, the authors want to apply a comparative case study to investigate the extent to which two m-learning methods are similar, and their main characteristics when designing interfaces. It also investigated their differences and the main purpose of those features that exist in one but not the other. This chapter also aims to evaluate the MobLearn method by comparing it to one of the existing m-learning methods that has the same goal. The researcher chose Stanton and Ophoff's method [4], which describes a high-level Mlearning design method containing eight steps. Comparative case studies include more than one case to produce generalizable knowledge about a specific topic. They emphasize comparison within and across various contexts. They encompass the analysis and synthesis of the similarities, differences, and the patterns across two or more cases that share a common focus or goal [4]. 
In this paper, section 2 describes the related work, section 3 discusses some key updates to the MobLearn method version 6 published in [3], section 4 explains the comparative study criteria, section 5 provides a discussion and an analysis of the results, section 6 explores the the final version of the MobLearn method's framework, including both the general and detailed steps, section 7 offers a comparison with other methods, and finally, section 8 offers a conclusion.

\section{Related work}

Online learning styles have evolved from E-learning to Mlearning which enables unlimited accessibility to learning content. This is majorly due to the advancement of technologies and enhanced mobile phones such as, smart devices and tablets. Consequently, traditional learning materials are being updated and redesigned to include compatibility with M-learning [5]. Nevertheless, the effects of certain mobile device features may hinder the efficacy of M-learning with issues relating to wireless internet connectivity, input/output systems, smaller sized screens, and battery life [6]. Taking these limitations into consideration is important during the modification of information to be delivered through mobile devices. Although several educational institutions have created their own applications, these apps have not taken into account several factors which contribute to the successful delivery of course materials through mobile devices [7]. In this section, there will be a description of the current methods, frameworks and guidelines that are available to design M-learning.

SOAP protocol enables the use of XQuery language, which then allows contents from a website to be adapted to the user's particular mobile device which works by transferring information structures from one operating system to another. However, this makes adaptation only possible for text formatted materials instead of rich formats as those contain multimedia [8]. Similar to the XQuery language, Huang et al. recommend the FWA algorithm which enables the conversion of different styles of web content to be adapted to any device [9]. Most research work has been focused on this area. For instance, an intelligent agent that can automatically alter and send all electronic messages to any device was created by Ally et al. In this case, the agent finds and chooses the optimal tool for conversion based on the software requirements and hardware limitations of each device [10]. On the other hand, this process can take anywhere from 10 to 30 minutes to convert each webpage for the particular mobile device, making it extremely time consuming. Nonetheless, a content adaptation system was designed that enables it to select the best version of the converted webpage for the mobile device in question. However, this process also has the major disadvantage of being very time consuming, offering users the option to skip any multimedia to be displayed in order to save time [11]. A system architecture for learning resource adaptation and delivery framework produced by a different study looks at some of the issues behind M-learning, for example, internet connectivity and wireless speed [12]. The study proposed engaged two process layers to guarantee the good quality of the materials being delivered: 1) a multimedia adaptation layer that considers the quality of the multimedia item, and 2) a learning object adaptation later that considers the quality of the learning objects. But while the research study considered the adaptation of existing websites to mobile devices, it did not take into account the design of original content delivery through mobile devices. Therefore, there are many issues due to this limitation, the process of transferring, and resulting interfaces system.

Many studies have also been conducted on creating different approaches on design and development of multimedia interfaces. Heller et al. divided multimedia into three main aspects: 1) media (text, sound, graphics, and motion), 2) context which considers target audience, discipline, interactivity, quality, usefulness, and aesthetics, and 3) media expression which includes elaboration, representation, and abstraction [13]. Their study proposed certain guidelines on how to plan particular media types based on information types. On the other hand, their study did not provide or design a method; they simply assessed educational multi-media. Nevertheless, according to Chen et al. combing e-learning materials online with different mobile technologies that can help contribute to an effective learning environment is certainly possible [6].

The Universal Instructional Design (UID) was adapted to M-learning concepts by Elias. The features of UID were designed to guide and help interface developers and designers who need to create educational material interfaces for a varied group of students [14]. Particularly useful in educational settings, the UID principles include the following:

1. equitable use,

2. flexible use,

3. simple and intuitive,

4. perceptible information,

5. tolerance for error,

6. low physical and technical effort,

7. community of learners and support, and

8. instructional climate.

The adapted UID has demonstrated good results with effective interfaces.

Campion suggests a method for designing tasks with multimedia integration using rules to guide the educational materials to a particular type of media [15]. A method and advisor tool for designing a multimedia user interface was also proposed by Sutcliffe et al. which considers user requirements, media selection, and data design when representing information [16]. Moreover, the latter method's advisor tool is a useful addition that helps in selecting the appropriate media to display the information content. Nonetheless, both of these methods to not consider the limitations of M-learning. Sutcliffe et al. offered a high-level M-learning approach that takes into account the course proposal and design as well as the objectives and usability measures [16]. Despite this approach, this method failed to take into account the following: the course structure, mapping information, and lesson analysis. In order to teach Dijkstra's shortest path algorithm using mobile devices, Seraj and Wong proposed 
a designing flash-based user interface; moreover, they also urge all designers to use UID principles when designing educational materials for mobile devices [17]. But while the strategy focuses on teaching Dijkstra's shortest path algorithm, it cannot be applied to design user interfaces for general educational material. Lee asserts that both technical and design should be factored in the decision to use mobile devices in learning environments [18]. The technical limitations can be attributed to the device functionality, and the design problems are based on the development of appropriate educational materials delivered via mobile devices. Lee provides a set of comprehensible instructions to follow when designing educational platforms on interfaces, taking into account the website browsers, and within the screen where to best position the features of the interface. Moreover, he also recommends UID designers to take into account which particular device they will consider before starting the design work.

There have been some research studies that concentrated on the production of design principles; in 2012, for example, there was design proposal for Mlearning practice tips [19]. Moreover, later in the same year, Ryokai et al. conducted a study that created the following design principles: "connect, contextualize access, capture, and multimodal" aiming to connect the gap between M-learning and what actually goes on in the classroom [20]. There was yet another study published in 2011 that included suggestions for designing M-leaning messages for different devices [21]. Wang and Shen's put 4 principles included:

Principle 1: "Design for the least common denominator"

M-learning materials should be designed in a format that is appropriate for all mobile devices.

Principle 2: "Design for E-learning, adapt for M-learning"

Utilize the same processes in E-learning for Mlearning, such as the iterative design approach which consists of design, creation and evaluation.

Principle 3: "Design short and condensed materials for smart phones"

Shorten and consolidate the course materials on the mobile devices screen by including images, audio notes and a summary of the materials.

Principle 4: "Be creative with $3 \mathrm{G}$ and $4 \mathrm{G}$ technologies"

$3 \mathrm{G}$ and $4 \mathrm{G}$ technologies have offered the designers the chance to run more sophisticated programs on mobile devices.

In 2010, web interfaces with responsive design were first initiated by [22]. Responsive web design entails flexible design interface that can be utilized pragmatically on all types of mobile device screens without compromising on content [23]. However, there is a lack of consideration for M-learning design principles; thus, this approach merely presents the design aesthetically on the mobile device. While it may be useful technology for designing M-learning materials, it can be further enhanced by taking into account certain M-learning design principles. These days, it is more common for app developers to consider design for mobile devices before desktop computers; even though designing for mobile devices may have more limitations. Essentially, this design strategy entails starting to create or design for the smallest screen first and progress towards larger formats.

To sum up, there is a dearth of studies on exploring design for M-learning interfaces that integrate multimedia formatting. It is recommended that further examination be conducted to analyze and explore other potential methods that could resolve design limitations. An ideal solution would include a comprehensible set of instructions to guide the selection and integration of media, address implementation issues, and evaluate other areas that need improvement while considering the features of mobile devices.

\section{Method for updating comparative study}

The researchers decided to update the MobLearn method presented in [2] \& [3]. This update improved this method so that it incorporated certain evolving features. The new version of the proposed method considers gamification and virtual reality in the mapping table and lesson plan in the information type table. It also includes an interaction table, which states all the possible technologies that could be used when interacting with multi-media.

The proposed method also considers pedagogical analysis; these techniques in the first step of the MobLearn method provides some guidance on how to analyse the educational material [24]. Pedagogical analysis is a process of breaking down the lesson into smaller sections and is defined as "the analysis of a given content material in any subject any topic carried out well in the spirit of the science of teaching (Pedagogy) is known by the term pedagogical analysis of the contents" [24].

\subsection{Comparative study design}

According to Goodrick (2014), a comparative case study fundamentally engages six steps, which are preferably undertaken in the following order:

\section{State the key evaluations}

This step is important to determine whether or not the use of comparative case studies techniques is a convenient design. The purpose of using comparative case studies may be either be an explanation, an interpretation, and/or a comparison [25]:

An explanation and an interpretation of the similarities and differences is determined between the cases in order to produce a holistic understanding of how the method functioned and how to direct additional implementation. The key evaluation question for the conducted comparative study in this research is as follows: what are the similarities and differences between these mlearning methods? The aim of this question is to develop a new, comprehensive version of the proposed method with the most beneficial characteristics after the interpretation of the results. 
- Comparisons can uncover certain explanatory propositions regarding how and why a method functioned in specific contexts. The key evaluation question for the conducted comparative study was what are the characteristics that make both of these methods suitable/unsuitable for the m-learning interface design? The aim of this question is to be able to identify any significant features not included by the MobLearn method that are seemingly significant for the m-learning interface design.

\section{Determine initial proposition}

This step aimed to clarify some of the initial propositions, which include a clarification of how the study was assumed to contribute to the results that will generate the intended goals [25]. In order to specify initial propositions, first a selection between a "within-group design" and a "between-group design" was made. This is a critical decision in all comparative studies as it has a direct impact on the quality of the data collected [26]. The within-group design was used to conduct this study. The time restrictions of the study, the sample size, and the nonexistence of individual differences are the reasons behind this choice of strategy. Additionally, this study was not funded so the researcher was unable to find a larger sample size. To overcome the disadvantages of this type of design, the researcher provided a quick tutorial to design participants before they started the study; this helped them understand how to use each method to design interfaces for m-learning. To reduce fatigue, a 10-minute break was allowed after each step and the researcher helped clarify any unclear ideas. The impact of the learning effect was considered very low in this study as the participants used two different methods to design the interfaces, which is the main topic of the study.

As discussed in Nagro and Campion, in a comparative study, the cases could be as few as two cases [25]. The researchers decided to conduct five comparative cases with different domains (anatomy, chemistry, genetic engineering, software engineering and mechanical engineering). Using several domains for the design process increases the opportunity to examine more of the information type and mapping tables.

The participants' criteria must be as represented in Table 1 to ensure the suitability and generality of the MobLearn method for most available mobile devices, the researcher decided to use five different models of mobile devices, as follows:

a. In the first sub-study (anatomy): the designer designed a set of interfaces for the Samsung Galaxy Tab Pro 5.

b. In the second sub-study (chemistry): the designer designed a set of interfaces for the Samsung Galaxy $\mathrm{S} 8+$.

c. In the third sub-study (genetic engineering): the designer designed a set of interfaces for Apple iPhone 8.

d. In the fourth sub-study (software engineering): the designer designed a set of interfaces for the Nokia 5 .

\begin{tabular}{|l|l|}
\hline Age & $20+$ \\
\hline Gender & Male or female \\
\hline Mental ability & Average \\
\hline Educational background & $\begin{array}{l}\text { School education as a } \\
\text { minimum }\end{array}$ \\
\hline Physical attributes & Normal \\
\hline Motivation & $\begin{array}{l}\text { Must have positive attitude } \\
\text { toward designing }\end{array}$ \\
\hline Personality & Patient \\
\hline Job & $\begin{array}{l}\text { Representative designers, } \\
\text { Junior designers, lecturers } \\
\text { has designing experiences. }\end{array}$ \\
\hline Computer usage & Average \\
\hline $\begin{array}{l}\text { Interface designing } \\
\text { experience }\end{array}$ & Any \\
\hline
\end{tabular}

Table 1: User Profile.

e. In the fifth sub-study (mechanical engineering): the designer designed a set of interfaces for the Huawei P10 lite Black.

III. Conducted the case study process

The cases took place in a quiet office with a computer on a desk and A4 paper to draw sketches. The researcher provided a quick tutorial on how to use both methods, and then presented the steps and the aim of the studies. Subsequently, the participants executed the design work before starting the initial sketches. After designing the interfaces using one of the provided methods, they were asked to conduct the other condition with the other method. After each case, the participants were interviewed to identify any difficulties, advantages, and disadvantages they had faced during the cases. During the interview, each participant needed to answer the Key Evaluation Questions. These two questions were as follows:

- What are the similarities and differences between these m-learning methods?

- What are the characteristics that make both of these methods suitable/not suitable for m-learning interface design?

The researchers conducted five cases, as mentioned previously, as the within-group design allows a small number of participants [26]. As a deep understanding of each case is required, comparative case studies tend to allow as few as two cases to be involved [25]. Each participant conducts one case.

\subsection{Collection and analysis of results}

After finishing all cases, the data was collected from the participants by interviewing them and encouraging them to comment on each method. The information was then analysed as qualitative data to improve the proposed method. The comparison spurred some new questions regarding the similarities and differences between the two cases, as discussed in the following sections.

\section{Findings}

The results of the five comparative cases conducted are summarized in Tables 2 and 3 below. Accordingly, the results were divided into negative and positive points for 


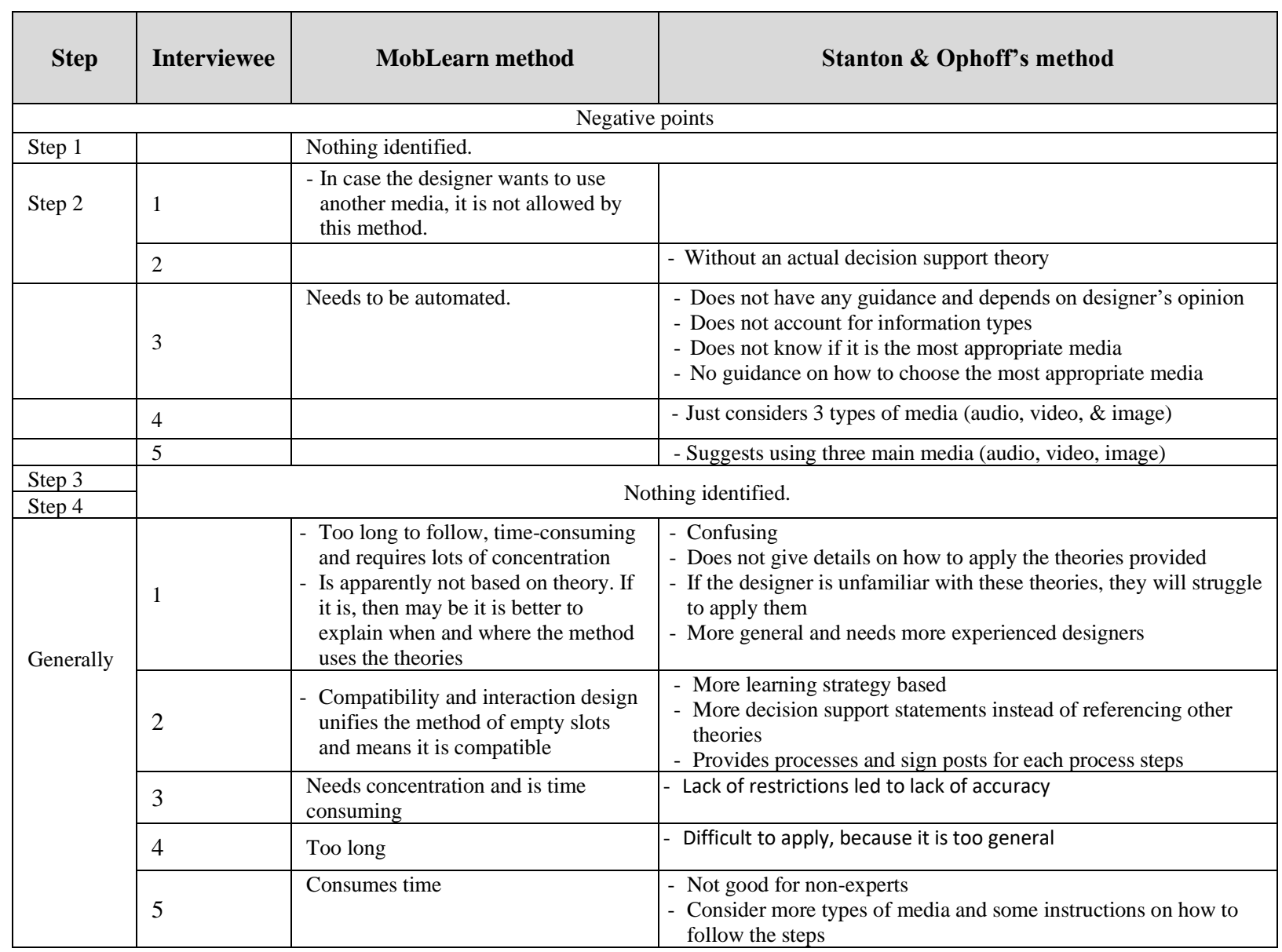

Table 2: Negative points identified by comparative study.

comparison, and were divided based on each step of the four steps method as presented in [2].

As shown in Tables 2 and 3, the results were categorized into negative and positive points to show the comparison.

\section{Discussion}

The comparative studies examined two m-learning methods that aim to design m-learning interfaces for a lesson. Both methods consisted of a set of steps based on several theories to guide the designing process. The participant designers were asked to identify the similarities and differences between both methods and specify the better choices for them. As argued by some participants, both of these methods produce interfaces suitable for m-learning. This is because both considered user-centred design [27], and the pedagogical analysis for the provided lesson. Moreover, both are based on all the steps in m-learning theories. Thus, both methods heed the importance of the lesson objectives and how to divide the lesson into smaller parts that are suitable to be represented on relatively small screens. Finally, both methods encourage designers to evaluate and test the system before finalizing it.

Most participants argued that the MobLearn method is time consuming as it has many steps and focused on more details. These reasons make this method more suitable for non-expert designers and designers with limited knowledge of how to use media for m-learning interfaces. Yet, one participant argued that the MobLearn method could be used by experts and non-experts, unlike the m-learning method by [4], which is not suitable for non-experts as it refers to a considerable number of design theories without explaining them. However, another designer thought that the MobLearn method has many restrictions to consider; thus, they inferred that it was more accurate in designing. This is why some participants suggested producing an automated version of the mapping process, so that when the designer chooses any information type, the system can show all the possible media they can utilize. This will be considered in our future research studies.

The main difference between these m-learning methods is in choosing multimedia. In the m-learning method by [4], the researchers referred to the design principles in both [19] and [20]. The principles are as follows: connect, contextualize access, capture, and multimodal. These principles connect the classroom with what is delivered via mobile devices for students and the importance of creating a personal connection to the material for the students by ensuring that it is relevant and meaningful. Multimodal refers to making the content accessible via multiple learning styles: visual, auditory and kinaesthetic [19]. These concepts are important in mlearning design; however, the researchers did not guide the designer on how to choose multimedia. Instead, they only 


\begin{tabular}{|c|c|c|c|}
\hline Step & Interviewee & MobLearn method & Stanton \& Ophoff's method \\
\hline \multicolumn{4}{|c|}{ Positive points } \\
\hline \multirow[t]{4}{*}{ Step 1} & 1 & $\begin{array}{l}\text { - Encourages the designer to look at the } \\
\text { material and divide them using some } \\
\text { pedagogical analysis } \\
\text { - Step } 1 \text { is a critical step. I consider it as the } \\
\text { base of the designing process. Designers need } \\
\text { to determine objectives, functional } \\
\text { requirements and information type }\end{array}$ & $\begin{array}{l}\text { - Encourages the designer to look at the material and divide } \\
\text { them using some pedagogical analysis } \\
\text { - In the other method the first step is indicated by green } \\
\text { boxes. It is concerned with analysing the pedagogy and it } \\
\text { relates them to the objective, which also gives the key } \\
\text { points for the designing process }\end{array}$ \\
\hline & 2 & $\begin{array}{l}\text { - Provides steps that are divided in a logical } \\
\text { order to start planning a lesson. }\end{array}$ & \\
\hline & 3 & $\begin{array}{l}\text { - Organises the delivery of the lesson } \\
\text { depending on objectives } \\
\text { - Depends on information type to choose media } \\
\text { - Shows the possible combinations of media }\end{array}$ & $\begin{array}{l}\text { - Organises the delivery of the lesson depending on } \\
\text { objectives }\end{array}$ \\
\hline & 5 & $\begin{array}{l}\text { - Supports the designers to know the objective } \\
\text { before designing commences, which leads } \\
\text { them to discover the content of the lesson } \\
\text { - Analysing the content is a good start } \\
\text { - Information type table made it easier for me to } \\
\text { choose multimedia }\end{array}$ & $\begin{array}{l}\text { - Supports the designers to know the objective before } \\
\text { designing commences, which leads them to discover the } \\
\text { content of the lesson } \\
\text { - Analysing the content is a good start }\end{array}$ \\
\hline \multirow[t]{5}{*}{ Step 2} & 1 & $\begin{array}{l}\text { - More determined by using information type } \\
\text { table and mapping table } \\
\text { - I found all multimedia I want in the mapping } \\
\text { table } \\
\text { - When it is my first time to design I will use } \\
\text { the MobLearn method, which makes me more } \\
\text { knowledgeable of all information types and } \\
\text { multimedia available } \\
\text { - Detailed mapping process is beneficial } \\
\text { - Suitable for mobile learning design as it } \\
\text { guarantees the choice of the most correct } \\
\text { media }\end{array}$ & $\begin{array}{l}\text { - Good as it gives the designer freedom to choose the } \\
\text { multimedia }\end{array}$ \\
\hline & 2 & $\begin{array}{l}\text { - Supports decision making in the process } \\
\text { - Connecting between the learning material and } \\
\text { the multimedia choice }\end{array}$ & \\
\hline & 3 & $\begin{array}{l}\text { - Guidance to choose the most appropriate } \\
\text { media, and it guides you step by step to do } \\
\text { this }\end{array}$ & \\
\hline & 4 & $\begin{array}{l}\text { - Mapping table is helpful, it helped me to } \\
\text { decide which media to apply }\end{array}$ & \\
\hline & 5 & $\begin{array}{l}\text { - Considers more than } 3 \text { media and on the } \\
\text { positive side it assists the designer with } \\
\text { choosing the media } \\
\text { - Considers the delivery of the content using } \\
\text { multimedia }\end{array}$ & $\begin{array}{l}\text { - Considers the delivery of the content using multimedia } \\
\text { - Easy to decide which media to use }\end{array}$ \\
\hline Step 3 & 4 & $\begin{array}{l}\text { - Analysing the lesson considering mobile } \\
\text { screen size }\end{array}$ & \\
\hline \multicolumn{4}{|c|}{ 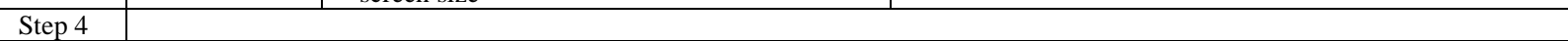 } \\
\hline \multirow[t]{5}{*}{ Generally } & 1 & $\begin{array}{l}\text { - Steps and sub-steps are clear to follow } \\
\text { - Suitable for mobile learning design }\end{array}$ & $\begin{array}{l}\text { - Not time consuming } \\
\text { - Not long to follow } \\
\text { - States some theory which is good to build a method on } \\
\text { - Suitable for mobile learning design }\end{array}$ \\
\hline & 2 & $\begin{array}{l}\text { - Appropriate for both lessons or complete } \\
\text { courses } \\
\text { - Colour coding to distinguish the steps } \\
\text { - Table layout }\end{array}$ & $\begin{array}{l}\text { - Colour coding } \\
\text { - Clarity of the main } \\
\text { Processes }\end{array}$ \\
\hline & 3 & $\begin{array}{l}\text { - Clear } \\
\text { - Accuracy in choosing media }\end{array}$ & $\begin{array}{l}\text { - Easier to follow as it does not contain many restrictions } \\
\text { - Not time consuming }\end{array}$ \\
\hline & 4 & $\begin{array}{l}\text { - A long method, which requires attention to } \\
\text { detail }\end{array}$ & \\
\hline & 5 & $\begin{array}{l}\text { - Follows some defaults steps, any expert } \\
\text { designer can follow them } \\
\text { - Could be used for non-expert and expert } \\
\text { designers, especially the second step } \\
\text { - Produces well-designed interfaces, I mean the } \\
\text { variety of multimedia available to choose } \\
\text { from }\end{array}$ & - Did not take long to apply \\
\hline
\end{tabular}

Table 3: Positive points identified by comparative study.

considered which three multimedia (video, audio, and image) could have been used [4]. On the other hand, the
MobLearn method starts this process by specifying for each piece of information a type by using a table that 


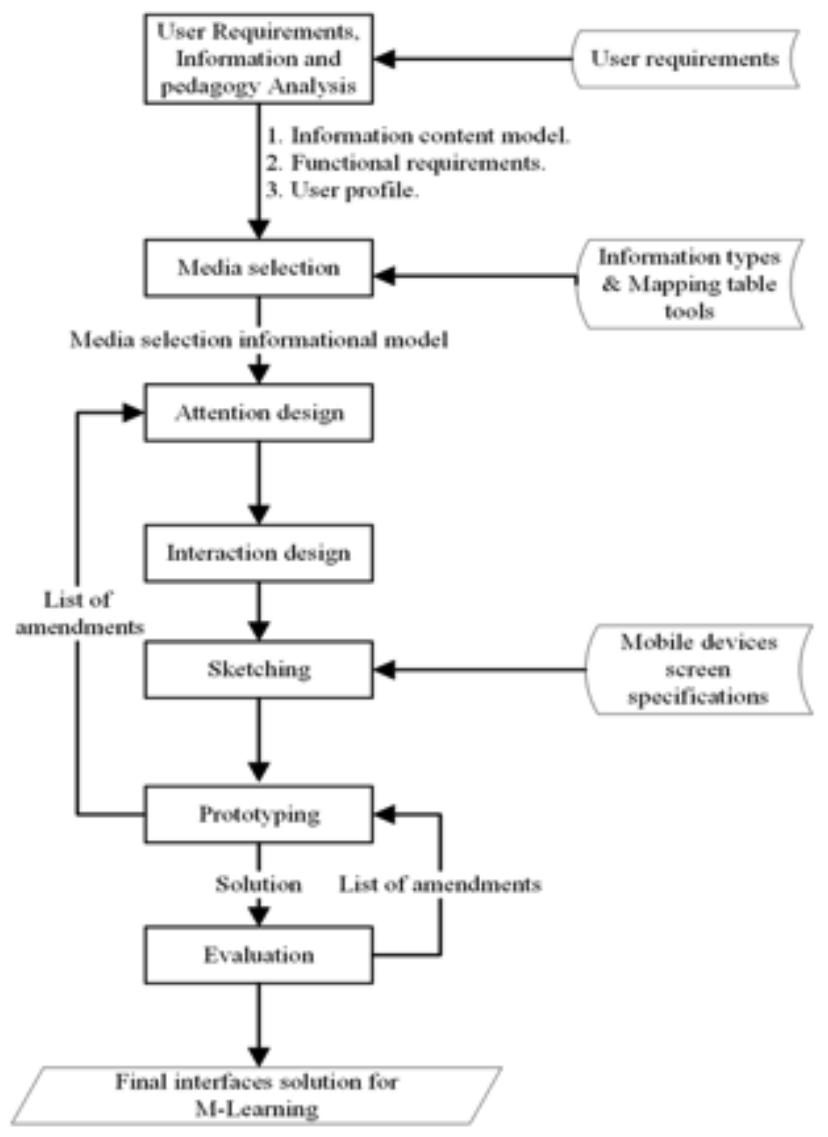

Figure 1: The Framework of the Method.

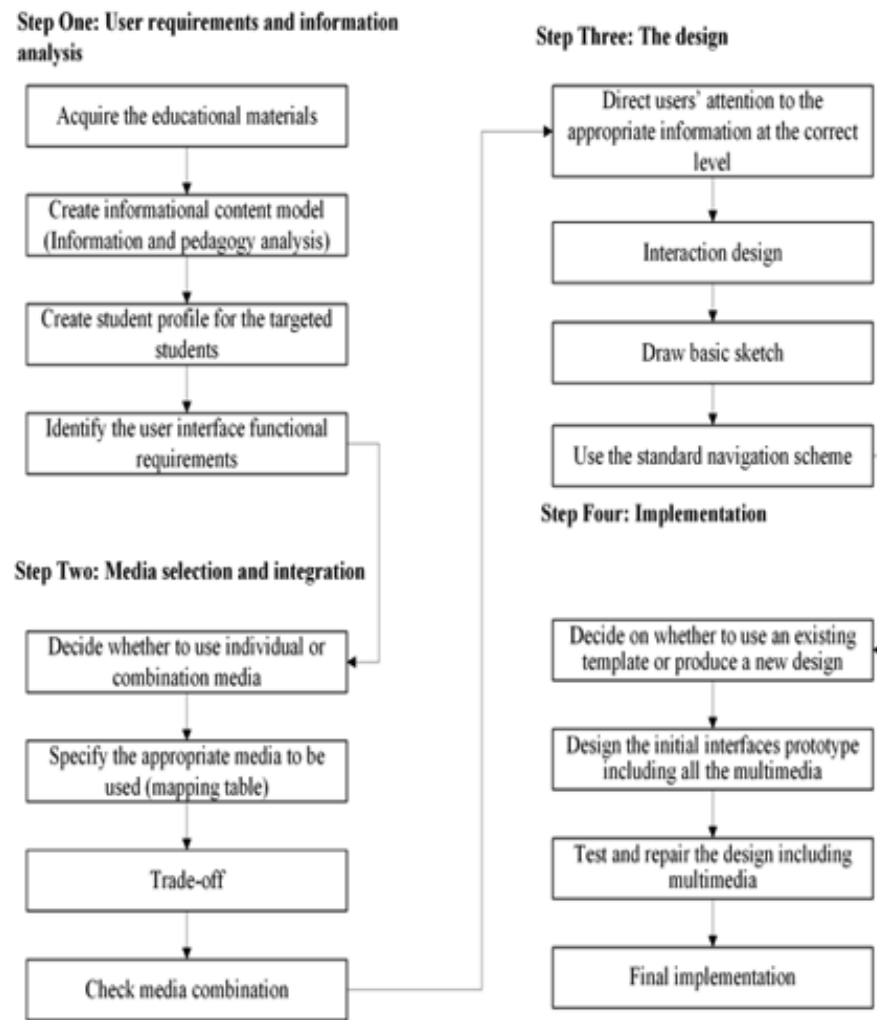

Figure 2: The Method's steps.

indicates all the possible information types, a description of these types, and some examples to help the designer with the decision making process. The MobLearn method then directs the designer to map each of the information types to set of possible multimedia by following a set of instructions provided. The participants of the comparative study agreed that these steps were clear, and that they supported the designers in choosing media by connecting the actual education material with the multimedia choices.

\section{Final method}

The following section presents the method's final version. As with the original prototype method in [2] this final version consists of three stages: 1) user requirements and information analysis, 2) media selection, integration and design, and 3) system implementation. The following section presents the method's framework.

\subsection{Method's framework and method's steps}

The method's framework shows the basic structure of the method (see Figure 1). It generally represents the main steps with the input and output associated with each process. The changes made to the final version were based on the results of the comparative study. Compared to the previous versions in [2], the first phase became user requirements, information, and pedagogy analysis, and the input for the media selection phase becomes information types and mapping table tools.

Figure 2 below portrays the steps of the method, where the first stage addresses step one, stage two addresses steps two and three in the method, and finally the third stage is addressed in step four.

\section{Comparison with related methods}

Table 4 below shows the main weaknesses in existing methods, found after conducting the literature review, and the gaps found and filled by the MobLearn method.

\section{Conclusion}

In this study, the authors used a comparative case study to explore the degree to which two methods of m-learning are identical as well as their key characteristics with reference to interface design. It also discussed their variations and the primary purpose of characteristics that occurs in one of them but not in the other.

The paper also assessed the process of MobLearn by contrasting it to one of the latest methods of m-learning that has the same purpose. The researchers chose the method of Stanton and Ophoff (2013), which defines a high-level method of m-learning design consisting of eight steps. The paper presented the final version of the method in two forms: high-level and framework overview of method steps. It gave an overview of the method, which represented the method as a framework. It also gave an overview of the method in the form of steps. In the final version, the research adds the mapping techniques for $\mathrm{m}$ learning design to the body of knowledge. Specifically, it supports studies that have suggested that mapping the information type to suitable media should also consider students' cognitive ability. The mapping techniques deal 


\begin{tabular}{|c|c|c|}
\hline $\begin{array}{l}\text { Weaknesses } \\
\text { and Gaps }\end{array}$ & Other Methods & MobLearn Method \\
\hline $\begin{array}{l}\text { Interaction } \\
\text { techniques for } \\
\text { mobile devices }\end{array}$ & $\begin{array}{l}\text { A multimedia design method for task requirement formulation, } \\
\text { media integration, and device combination (TRIUMPH) by } \\
\text { Campion (1999) and a method and advisor tool for multimedia } \\
\text { user interfaces by Sutcliffe et al. (2006). Both consider } \\
\text { interaction techniques. However, both methods do not consider } \\
\text { new interaction techniques such as accelerometer, haptic and } \\
\text { gestural. The second method has a limitation, as was necessary } \\
\text { more advice on interaction and dialogue design (Sutcliffe et al., } \\
\text { 2006). }\end{array}$ & $\begin{array}{l}\text { MobLearn method overcomes these limitations in the } \\
\text { interaction table }\end{array}$ \\
\hline $\begin{array}{l}\text { Task scenarios } \\
\text { for mapping } \\
\text { information to } \\
\text { multimedia }\end{array}$ & $\begin{array}{l}\text { A multimedia design method for task requirement formulation, } \\
\text { media integration, and device combination (TRIUMPH) by } \\
\text { Campion (1999), a method and advisor tool for multimedia } \\
\text { user interfaces by Sutcliffe et al. (2006) and a framework for } \\
\text { mapping multimedia to educational concepts by Onyekaba, } \\
\text { Campion and Atkins (2016). All of these consider task } \\
\text { scenarios to produce multimedia interfaces but not for m- } \\
\text { learning devices. } \\
\text { Sutcliffe et al. (2006) method did not consider mapping } \\
\text { information to multimedia as it depends on heuristics and a } \\
\text { decision tree. The framework for mapping multimedia to } \\
\text { educational concepts by Onyekaba, Campion and Atkins did } \\
\text { not consider m-learning [28]. }\end{array}$ & $\begin{array}{l}\text { MobLearn method considers task scenarios to } \\
\text { produce multimedia m-learning interfaces. In the } \\
\text { second step, it considers task scenarios to map the } \\
\text { educational concepts to multimedia for m-learning } \\
\text { devices. }\end{array}$ \\
\hline Further analysis & & $\begin{array}{l}\text { The proposed method gives details on how to analyze } \\
\text { the educational materials (pedagogical analysis), } \\
\text { following a method adapted from Bhowmik et al. } \\
\text { (2013). The pedagogical analysis takes place in the } \\
\text { first step and advises how to decide on information } \\
\text { type. }\end{array}$ \\
\hline $\begin{array}{l}\text { Selection } \\
\text { guidelines, } \\
\text { general and } \\
\text { validating } \\
\text { heuristics for } \\
\text { mapping }\end{array}$ & $\begin{array}{l}\text { The multimedia design method for task requirement } \\
\text { formulation, media integration, and device combination } \\
\text { (TRIUMPH) by Campion (1999) depends on media model for } \\
\text { mapping. Sutcliffe et al. (2006) method depends on guidelines } \\
\text { and heuristics. The framework for mapping multimedia to } \\
\text { educational concepts by Onyekaba, Campion and Atkins } \\
\text { (2016) depends on a framework. }\end{array}$ & $\begin{array}{l}\text { The proposed method gathers all the information } \\
\text { related to mapping in exciting methods and produces } \\
\text { a mapping table to map the educational concept to } \\
\text { multimedia for m-learning devices, not for general } \\
\text { interfaces. } \\
\text { It also suggests mapping to new technological } \\
\text { practice such as gamification and virtual reality. }\end{array}$ \\
\hline $\begin{array}{l}\text { Does the method } \\
\text { address } \\
\text { integration? }\end{array}$ & $\begin{array}{l}\text { Some of the methods address integration; however, they leave } \\
\text { it to the designer to decide which media combination to use. }\end{array}$ & $\begin{array}{l}\text { The proposed method allows the designer to go } \\
\text { through several steps to produce one optimal solution } \\
\text { for integration. depending on the most frequently } \\
\text { occurring media and recommended media. }\end{array}$ \\
\hline $\begin{array}{l}\text { New technology } \\
\text { considered }\end{array}$ & N/A & $\begin{array}{l}\text { The proposed method considers gamification and } \\
\text { virtual reality in the mapping table, to help the } \\
\text { designer to decide when to use them and what } \\
\text { educational concepts are most suitable for them. }\end{array}$ \\
\hline
\end{tabular}

Table 4: Results of comparison of MobLearn method with related methods.

with a clear set of information types and the following set of media: animation, non-realistic audio, charts, diagrams, graphs, lists, realistic audio, network charts, maps, music, photographs, sketches, speech, tables, text, videos, captions, gamification and virtual reality.

\section{Acknowledgement}

We thank Dr. Russell Campion for his tremendous support and feedback during this research study.

\section{References}

[1] M. AlDekhail (2015). "E-Learning Assistance and Application for the Auditory-Impaired Population: A Review with Recommendations." Journal of Basic Applied Scientific Research (JBASR) 5(3), pp. 36-53 [online]. Available at: https://www.textroad.com/

[2] S. Nagro and R. Campion (2017) 'A method for multimedia user interface design for mobile learning.' IEEE: Computing Conference. London, United
Kingdom, pp. 585-590. [online]. Available at: DOI: 10.1109/SAI.2017.8252155

[3] S. Nagro and R. Campion (2017) "Evaluation of multimedia user interface design method for mobile learning." In: Proceeding of The 11th annual International Technology, Education and Development Conference (INTED). Valencia, Spain, 6-8 March 2017, pp. 1533-1541. [online] Available at: DOI: 10.21125/inted.2017.0494

[4] G. Stanton and J. Ophoff, (2013) 'Towards a Method for Mobile Learning Design.’ Informing Science and Information Technology, 10, pp. 501-522. [online] Available at: DOI: $10.28945 / 1825$

[5] Y Jeng, T. Wu, Y. Huang, Q. Tan, and S. Yang (2010). "The Add-on Impact of Mobile Applications" in Learning Strategies: A Review Study." Educational Technology \& Society, 13 (3), 3-11. [online] Available at https://www.researchgate.net/

[6] G.D. Chen, C.K. Chang, and C.Y. Wang (2008) "Ubiquitous learning website: Scaffold learners by mobile devices with information-aware techniques", 
Computers \& Education, vol. 50, no. 1, pp. 77-90. [online] Available at:

DOI: 10.1016/j.compedu.2006.03.004

[7] J. Cheon, S. Lee, S. Crooks, and J. Song (2012). “An Investigation of Mobile Learning Readiness in Higher Education Based on the Theory of Planned Behavior.: Computers \& Education 59(3), pp. 1054-1064. [online] Available at:

DOI: 10.1016/j.compedu.2012.04.015

[8] T. Lemlouma and N. Layaida (2004) "Context-aware adaptation for mobile devices", in IEEE International Conference on Mobile Data Management, Saint Martin, France, pp. 106 - 111. [online] Available at: hal.inria.fr/inria-00423390

[9] Y. Huang, Y. Kuo, Y. Lin, and S. Cheng (2008) "Toward interactive mobile synchronous learning environment with context-awareness service", Computers \& Education, vol. 51, no. 3, pp. 12051226. [online]. Available at: DOI:10.1016/j.compedu.2007.11.009

[10] M. Ally, F. Lin, R. McGreal, B. Woo, and Q. Li (2005) 'An intelligent agent for adapting and delivering electronic course materials to mobile learners', in Mobile Technology: The future of learning in your hands 2005, Capetown, South Africa. [online]. Available at: https://citeseerx.ist.psu.edu/

[11] W.Y. Lum, and F.C.M. Lau (2002). A context-aware decision engine for content adaptation. IEEE Pervasive Comput., 1(3), pp.41- 49. [online] Available at: DOI:10.1109/MPRV.2002.1037721

[12]Z. Gang and Y. Zongkai (2005) "Learning Resource Adaptation and Delivery Framework for Mobile Learning", in 35th ASEE/IEEE Frontiers in Education Conference, Indianapolis, IN. [online] Available at: DOI:10.1109/FIE.2005.1612035

[13] R. Heller, C. Martin, N. Haneef, and S. Gievska-Krliu (2001) "Using a theoretical multimedia taxonomy framework", Journal of Educational Resources in Computing, 1(1), p. 6. [online] Available at: DOI: 10.1145/376697.376701

[14] T. Elias (2011) "Universal Instructional Design Principles for Mobile Learning", The International Review of Research in Open and Distributed Learning, 12 (2), pp. 144-156. [online] Available at: files.eric.ed.gov/fulltext/EJ920738.pdf

[15]R. Campion 'TRIUMPH: A multimedia design method for task requirement formulation, media integration, device combination, and practical implementation design issues', Ph.D., Staffordshire University, 1999. Available [online] Electronic Dissertation

[16] A. Sutcliffe, S. Kurniawan, and J. Shin (2006). “A method and advisor tool for multimedia user interface design." in International Journal of Human-Computer Studies, 64(4), pp.375-392. [online] Available at: DOI: 10.1016/j.ijhcs.2005.08.016

[17] M. Seraj and C. Wong (2015) "A study of User Interface Design Principles and Requirements for Developing a Mobile Learning Prototype", in Proceeding of the International Conference on Computer and Information Science, Kuala Lumpur,
Malaysia, pp. 1014-1019. [online] Available at: DOI:10.1109/ICCISci.2012.6297174

[18] S. Lee (2015) "Design Guidelines to Consider for Mobile Learning", Info.alleninteractions.com, 2015. [Online]. Available at: https://blog.alleninteractions.com/

[19] J. Killilea (2012). Leveraging mobile devices for asynchronous learning: Best practices. scs.org. University of Central Florida. [online] Available at: http://www.scs.org/

[20] K. Ryokai, A. Agogino, and L. Oehlberg (2012) 'Mobile learning with the engineering pathway digital library.' International Journal of Engineering Education, 28(5), pp.1119-1126. [online] Available at: https://people.ischool.berkeley.edu/

[21] M. Wang and R. Shen (2011) "Message design for mobile learning: Learning theories, human cognition and design principles", British Journal of Educational Technology, 43(4), pp. 561-575. [online] Available at: DOI: $10.1111 / \mathrm{j} .1467-8535.2011 .01214 . \mathrm{X}$

[22]E. Marcotte (2010) "Responsive Web Design", Alistapart.com, [Online]. Available at: http://alistapart.com

[23] K.V. Natda (2013). "Responsive Web Design", Eduvantage, 1(1). [online] Available at: DOI:10.11635/2319-9954/1/1/18

[24] M. Bhowmik, B. Banerjee, and J. Banerjee (2013) "Role of Pedagogy in Effective Teaching," Education Research and Review, 2(1), pp. 1-5. [online] Available at: http://basicresearchjournals.org/

[25]D. Goodrick (2014) Comparative Case Studies: Methodological Briefs - Impact Evaluation No. 9, Methodological Briefs (No. innpub754). [online] Available at: https://www.unicef-irc.org/

[26] J. Lazar, J. Feng and H. Hochheiser (2017) Research methods in human computer interaction. 2nd ed. USA: Morgan Kaufmann.

[27] A. Errity (2016) "Human-computer interaction," in I. Connolly, M. Palmer, H. Barton, and G. Kirwan (Eds.), An introduction to cyberpsychology. Oxon: Routledge, pp.241- 254.

[28] C. Onyekaba, R. Campion, and A. Atkins (2016) “A framework for mapping multimedia to educational concepts", Proceedings of INTED2016, Valencia, Spain, 7 - 9 March, 2016. pp. 7987 - 7996. Available at: DOI:10.21125/inted.2016.0880 
